\title{
A Study to Determine the Existence of an Azeotropic R-22 "Drop-In" Substitute
}

Min Soo Kim

Graham Morrison

William J. Mulroy

David A. Didion

Building Environment Division

Building \& Fire Research Laboratory

March 1996

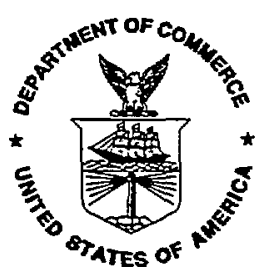

U.S. Department of Commerce

Ronald H. Brown, Secretary

Technology Administration

Mary L. Good, Under Secretary for Technology

National Institute of Standards and Technology

Arati Prabhakar, Director
Prepared for:

Electric Power Research Institute Terry G. Statt, Project Manager

Customer Systems Division 3412 Hillveiw Avenue

Palo Alto, CA 94303 


\section{TABLE OF CONTENTS}

ABSTRACT $\ldots \ldots \ldots \ldots \ldots \ldots \ldots \ldots \ldots \ldots \ldots \ldots \ldots \ldots \ldots \ldots \ldots$ iv

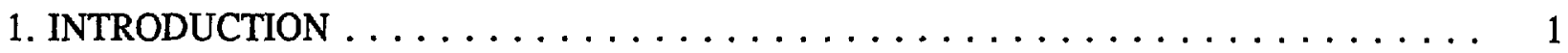

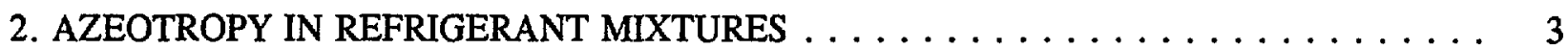

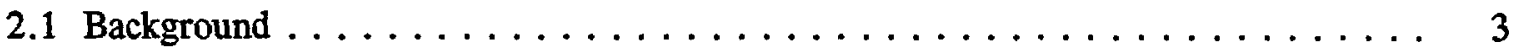

2.2 A Method For Locating Azeotropes . . . . . . . . . . . . . . . 5

2.3 Selection of Azeotropes for Experimental Evaluation . . . . . . . . . . . . . 10

2.4 Verification of Azeotropes for Experimental Evaluation $\ldots \ldots \ldots \ldots \ldots \ldots$

3. PERFORMANCE PREDICTION $\ldots \ldots \ldots \ldots \ldots \ldots \ldots \ldots \ldots \ldots \ldots$

4. LABORATORY PERFORMANCE EVALUATION $\ldots \ldots \ldots \ldots \ldots \ldots \ldots$

5. PERFORMANCE RESULTS AND DISCUSSION $\ldots \ldots \ldots \ldots \ldots \ldots \ldots \ldots \ldots$

5.1 High Temperature Cooling Test Results . . . . . . . . . . . . . . . . 17

5.2 High Temperature Heating Test Results . . . . . . . . . . . . . . . 18

5.3 Liquid-Line/Suction-Line Heat Exchange . . . . . . . . . . . . . . . . . . . 20

5.4 Performance Simulation of Experimental Results $\ldots \ldots \ldots \ldots \ldots \ldots$

6. FLAMMABILITY MEASUREMENTS $\ldots \ldots \ldots \ldots \ldots \ldots \ldots \ldots$

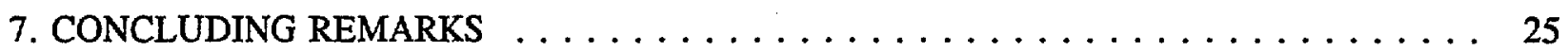

NOMENCLATURE $\ldots \ldots \ldots \ldots \ldots \ldots \ldots \ldots \ldots \ldots \ldots \ldots \ldots \ldots \ldots \ldots \ldots$

ACKNOWLEDGEMENT . . . . . . . . . . . . . . . . . . . . . . . . 29

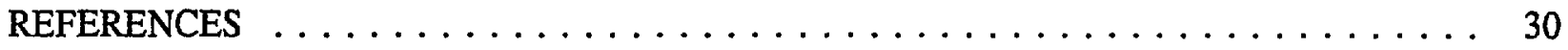

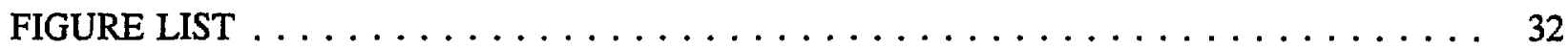



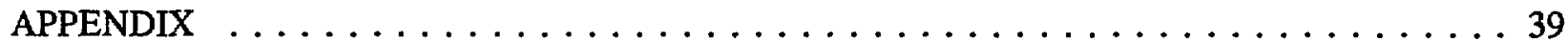




\begin{abstract}
The reduction in chlorofluorocarbon (CFC) and hydrochlorofluorocarbon (HCFC) production and the scheduled phase-out of these ozone depleting refrigerants requires the development and determination of environmentally safe refrigerants for use in heat pumps, water chillers, air conditioners and refrigerators. Azeotropic mixtures are attractive as alternative refrigerants because they behave very nearly as pure materials. A simple correlative scheme that allows one to judge whether or not an azeotrope is likely in a binary refrigerant mixture is discussed. This paper presents laboratory and computer simulation evaluation of two of the azeotropic refrigerant mixtures which were identified, HFC-134a $(1,1,1,2$-tetrafluoroethane) with R-290 (Propane) and HFC-134a with R-600a (Isobutane), in a generic heat pump apparatus. A third azeotropic mixture, HFC-134a with R-C290 (Cyclopropane) is examined by computer simulation only. The performance characteristics of these azeotropes were compared with pure CFC-12, HFC-134a, HCFC-22, and R-290 at high temperature cooling and heating conditions. Use of liquid-line/suction-line heat exchange was evaluated.
\end{abstract}

Key words : air conditioning, azeotropic refrigerant mixtures, heat pump, alternative refrigerants, refrigeration, working fluids, HFC-134a, propane, cyclopropane, isobutane 


\section{INTRODUCTION}

In the search for alternative refrigerants, emphasis has been put on finding safe (i.e., nonflammable and nontoxic), chlorine-free, single-component fluids with saturation pressures similar to those of the refrigerants which are replaced. The most successful, to date, has been the development of $\mathrm{HFC}-134 \mathrm{a}$ as an alternative to $\mathrm{CFC}-12$. However, even this alternative has its limitations if it is intended as a "drop-in" for existing CFC-12 machines. Most significant is the lack of mineral oil solubility with this or any other chlorine-free refrigerant. Although ester based lubricants have been developed recently, in the drop-in application (i.e., one in which an alternative would be used in existing equipment originally designed for a CFC), a thorough flushing of the mineral oil would be necessary, which may prove difficult if not impractical in many cases. Also, this ethane based refrigerant alternative has, inherently, a lower evaporator vapor pressure and a less steep liquid saturation pressure curve on a pressureenthalpy diagram than the methane based CFC-12. This implies more flash gas during the expansion process and a lower suction gas density, thus a loss in capacity relative to CFC- 12 . The HCFC-22 alternative search has been far more difficult, with no known single-component fluid having a reasonably close saturation pressure curve. As a result, mixing of two or more components to obtain all the desired working fluid properties has become important. Several zeotropic mixtures of compositions resulting in vapor pressures similar to HCFC-22 are the only possible drop-in's known at the present time (Domanski and Didion, 1993). These are being evaluated by industry rather reluctantly because of the inherent complexity of maintaining the design composition in the field during leakage and partial recharging operations.

Among the different types of mixtures, azeotropes are preferred because they retain both 
vapor and liquid at the same composition, throughout the phase change; consequently they are no different from single component refrigerants for all practical purposes. A simple correlative scheme that allows one to judge whether or not an azeotrope is likely in a binary refrigerant mixture has been developed (Morrison and McLinden, 1993) by which virtually all of the halogenated hydrocarbon azeotropic pairs have been identified and so it is interesting to explore halogenated hydrocarbon and hydrocarbon pairs to determine if any of their azeotropes can match the performance of the fluids slated for elimination. Such a search has a high likelihood of success because azeotropes are most probable to exist between molecules with large differences in polarity.

Hydrocarbons are environmentally safe and will not have to be recycled. Incorporating a hydrocarbon within an azeotrope is also likely to offer the additional advantage of making the mixture soluble with mineral oil. Thus, if this type of azeotrope has a similar performance to the refrigerant it is replacing, it could act as a true drop-in. Of course, the disadvantage of using a high percentage of hydrocarbon in any mixture is that it is likely to be flammable. Although current practice in the United States does not include the use of flammable refrigerants for residential or commercial applications, many industrial applications do. Furthermore, the presence of the halogen atoms will certainly mitigate the flammability hazards, by reducing the combustion energy and flammability limits, compared with the pure hydrocarbons.

The quantification of the performance descriptors, particularly coefficient of performance (COP) and capacity of two such azeotropes is the subject of this report. 


\section{AZEOTROPY IN REFRIGERANT MIXTURES}

Sections 2.1 through 2.3 are a condensation of the method developed for identifying azeotropes as part of this joint EPRI/NIST project. This method is fully explicated in (Morrison and McLinden, 1993).

\subsection{Background}

The simplest mixture model, Raoult's Law, provides a basis for estimating the bubble pressures of nearly ideal mixtures. This "rule of thumb" proposes that, for liquid mixtures of compounds with similar chemical nature at temperatures far from the critical point of any of the components, the vapor pressure will be a linear combination by mole fraction of the pure component vapor pressures. By invoking Dalton's Law and the ideal gas law, one can calculate the composition of the vapor that is in equilibrium with the liquid.

Although the behavior of many mixtures can be approximated by the Raoult-Dalton model, departure from that model is the norm. In some mixtures, the departure is so large that the bubble pressure exceeds the vapor pressure of the most volatile component; there are likewise mixtures for which the bubble pressure is lower than the vapor pressure of the least volatile component. If there is an extremum in the bubble point locus in the pressure-composition diagram, the liquid and vapor phases will have the same composition, and the dew point locus will be horizontal and tangent to the bubble locus, as described by the Gibbs-Konowalow relationships. It is this condition, where the compositions of the two phases are identical that defines the azeotrope. The positive extremum in pressure at fixed temperature is complemented by a negative extremum in temperature at fixed pressure and vice versa for 
the negative extremum in pressure.

Because the liquid and vapor have the same composition at the azeotropic condition, the composition and boiling temperature will remain unchanged with the progressive boiling at constant pressure. While an azeotrope presents problems to one interested in separation of the components, it can be used to advantage by one interested in mixtures whose properties remain fixed.

Whether or not a mixture has an azeotrope depends on the relation between the departure from the Raoult law behavior and the difference in the vapor pressures of the components of the mixtures. If the difference in vapor pressures is small, the departure from ideality that leads to an extremum can also be small. In the special case of a binary mixture in which the vapor pressures of the components at a particular temperature are identical, a condition known as a "Bancroft point," any departure from ideality will lead to an extremum. Unless an extraordinary set of conditions were to prevail, a mixture with a Bancroft point will display azeotropic behavior.

Systems with Bancroft points represent only a fraction of all mixtures that have azeotropes. Although azeotropes are more likely to occur when the vapor pressures of the pure constituents are close to one another, that alone does not guarantee the appearance of the phenomenon. Conversely, a large difference in vapor pressures does not assure the absence of an azeotrope.

The azeotropic composition changes with temperature. As the temperature is raised, a pressure-maximum (or positive) azeotrope in a binary mixture typically moves toward the component whose vapor pressure is changing more rapidly with temperature (usually the more 
volatile component); a pressure-minimum (or negative) azeotrope usually moves toward the component whose pressure is changing less rapidly with temperature (usually the less volatile component). Unless another feature in the phase diagram intervenes, the azeotrope can move to the edge of the phase diagram and disappear altogether. The refrigerant mixture dichlorodifluoromethane (R12) plus chlorodifluoromethane (R22) displays such behavior; the positive azeotrope disappears above $30^{\circ} \mathrm{C}$. If there is a Bancroft point, the azeotrope can emerge from the saturation boundary of one component and disappear into the saturation boundary of the other component. The mixtures methanol plus acetone and 2,4-dimethylpentane plus 2,2,3-trimethylbutane display this behavior.

\subsection{A Method For Locating Azeotropes}

In this section, the relation between the Carnahan-Starling-Desantis equation of state mixture interaction parameter, $f_{12}$, and azeotropy will be examined [Morrison and McLinden, 1993]. The part of the phase diagram that will be searched for azeotropes is determined by several practical factors. First, the azeotropes among the halogenated hydrocarbons, both fully and partially substituted, are primarily positive pressure azeotropes; examples of negative azeotropy do occur in mixtures of the halogenated hydrocarbons with other chemical families. By confining the search to positive azeotropes, the important part of the phase diagram will be in the region of the more volatile of the two components. The second criterion is to ask whether the azeotrope will appear within the operating range of interest. Working fluids are usually chosen so that the normal boiling temperature is not higher than the lowest temperature encountered in the refrigeration machinery ( $R-11$ and $R-123$ are exceptions to this rule because 
of their high efficiency). Thus the nature of the phase diagram in the region of the normal boiling point of the more volatile component will indicate whether or not there is an azeotrope in the operating range of the machinery.

The appearance of an azeotrope can be connected to the value of, which must exceed a threshold value for the positive azeotropic locus to end at the normal boiling point of the more volatile component. This limiting value of $\mathrm{f}_{12}$ is determined by finding the condition for which the $\mathrm{K}$-factor, the ratio of the mole fractions of the minor component in the liquid and vapor phases, equals unity in the limit of the pure solvent. This quantity is readily calculated from the chemical potential of the minor component.

Figure 1 shows a grid of 25 compounds that have been used as refrigerants or have been proposed as alternatives. They have been ordered according to normal boiling point from the most volatile on the left to the least volatile on the right. The normal boiling temperature has been noted in kelvins to the left of each compound. Each space in the grid represents a mixture. The quantity entered in each space is the value of $f$ necessary to produce an incipient azeotrope at the boiling point of the more volatile (lower boiling) component. Those mixtures noted with a temperature instead of a value of $f$ indicates a pair with a Bancroft point at that temperature. As one would expect, for pairs with similar boiling points, the necessary value of $f$ is small; for pairs with quite different boiling points, the value is large.

Figure 2 shows an arrangement of experimental $f_{12}$ for 24 mixtures where the correlating variable, the ratio of the dipole moment to the excluded molecular volume, $\mu / \mathrm{b}$, depends on both polarity and size. Since the parameter $b$ is temperature dependent as it has been applied to this equation of state, the ratio has been evaluated at $0.75 \mathrm{~T}$, which is somewhat higher than the 
normal boiling temperature and in the range where most measurements have been made. For those species with temperature dependent dipole moments, the value of $\mu$ at $0.75 \mathrm{~T}$ has been used. Each of the refrigerants with a non-zero value of $\mu / \mathrm{b}$ has been located along the hypotenuse where, of course, the value of $\mu / \mathrm{b}$ is the same on both axes. A mixture can be located by drawing the horizontal and vertical axes that pass through the components located on the hypotenuse. Note that every mixture containing one or the other of the components falls on these axes. Where the two sets of axes intersect (the example of R12 plus R22 is shown in Figure 2) is the grid point for that mixture. With a few exceptions, mixtures with similar values of $\mathrm{f}$ tend to be near one another in the space defined by the ratio $\mu / \mathrm{b}$.

A value of $f_{12}$ can be estimated for a mixture where there is no experimental information by noting the relation between the grid point and the loci of constant $\mathrm{f}$ in the diagram. These loci reflect the trend that $f_{12}$ tends to increase from left to right and from top to bottom. The loci have been drawn parallel to one another, however, they are not parallel to the hypotenuse of the triangular representation as one would intuitively expect. The direction and locations have been gauged primarily by those mixtures for which $\mathrm{f}_{12}=0.0$ and $=0.04$. The hypotenuse of the diagram does not apply to the mixtures of a species with itself.

One can make a heuristic argument for this strong correlation. The dimension of the correlating quantity has units of surface charge density. One might imagine these molecules as nearly spherical objects where the separated charge that gives rise to the dipole moment is distributed over the surface; for two molecules with similar surface charge densities, the larger molecule will have the larger dipole moment. If one argues that the dominating close-range attractive interaction between molecules is between the surface charge distributions, one could 
argue that the departure from ideality would be dependent on the difference in this quantity.

One would expect then that this correlation works best where the dipolar part of the molecular interaction plays an important, perhaps dominant, role in the properties of the mixture, that is, where at least one of the components is highly polar. One would expect the correlation to be poorest for mixtures where neither of the species is polar. For example, mixtures of saturated hydrocarbons are nearly ideal but mixtures of saturated hydrocarbons with fully fluorinated hydrocarbons are notoriously non-ideal. Both of these families of mixtures would be in the lower left apex of the diagram and would not be differentiated from one another in this correlation. Departures from the pattern shown in Figure 2, such as the mixtures R12 plus R13 and R13 plus R14, and the lack of $45^{\circ}$ symmetry in this representation may result from the inability of this heuristic model to incorporate all the important features of the molecular interaction. Nevertheless, this graphical correlation allows one to estimate the value of $f$ with a certainty of 0.015 , which, as shown by Pesuit, is as well as one can expect from any scheme to estimate the mixture interaction parameter.

A grid similar to the one in Figure 1 can be created for values of $f_{12}$ estimated from Figure 2. This is shown in Figure 3. Mixtures that contain species with temperature dependent dipole moments present somewhat of a problem, because specific interactions are clearly not with the "average" molecule while the entire fluid probably does sense the "average." We have tried to strike a compromise by estimating $f_{12}$ both by using the average value of the dipole moment (the species noted in Figure 2) and by using the average of the $f_{12}$ 's for the individual conformers. The two schemes typically yield similar values for $f_{12}$. When there was a difference between the two, the choice in favor of the higher value was made. Meyer and Morrison (1991) discuss 
temperature dependent dipoles in detail.

Figure 4 shows the result of comparing Figures 1 and 3. Grid points noted with a "B" indicate an azeotrope associated with a Bancroft point. Mixtures noted with a lower case "a" indicate that the values of $f_{12}$ in Figures 1 and 3 were within 0.01 of one another so that one would expect a shallow azeotrope at best near the normal boiling point of the more volatile component. An upper case "A" indicates azeotropy extending to higher temperatures. Here the estimated value of $f$ in Figure 3 was more than 0.01 greater than the value in Figure 1. A position marked with an underlined character indicates that an azeotrope has actually been observed for that mixture. There were no cases where an azeotrope reported in Downing (1988) was not predicted. The grid points not marked by an "a," "A," or "B" indicate mixtures for which an azeotrope is unlikely. Those grid points marked with an asterisk indicate the data set that produced Figure 2. One sees at once that a small set of information has led to the successful prediction of many azeotropes. The same correlation also suggests many other mixtures that are likely to be azeotropic. One could further examine Figures 1 and 3 to predict mixtures where, although an azeotrope is unlikely, the two-phase region would, nonetheless, be narrow. Such nearly azeotropic mixtures would also be of great interest in refrigeration applications. In these mixtures the predicted value of $f_{12}$ would be roughly 0.01 less than the value required for an azeotrope. As one would expect, the density of azeotropes is highest along the hypotenuse of Figure 4 . Here, an azeotrope can occur when there is only a small departure from ideality. Proximity of the mixture to the hypotenuse does not assure an azeotrope. For example, the mixture R22 plus R143a is predicted to be nearly ideal even though many azeotropes are in nearby mixtures. Mixtures of highly polar components, which correspond to 
mixtures near the top of the field in Figure 2, tend to be nearly ideal. Azeotropes that appear far from the hypotenuse are typically mixtures of non-polar species and very polar species (bottom right part of Figure 2).

\subsection{Selection of Azeotropes for Experimental Evaluation}

The search for azeotropes among the multitude of possible candidates from two different chemical families quickly becomes unwieldy. Therefore several rules for selection must be established even if only binary pairs are to be considered, as was the case here. First, only simple molecules were considered so as to keep the specific heat of both liquid and vapor relatively close to that of the CFC being replaced; otherwise the amount of flash gas and lost work of compression in the fluid's basic vapor compression cycle will render the performance so low in COP that the system will be noncompetitive (McLinden and Didion, 1987). Both fluids to be mixed together should have reasonably close or slightly higher normal boiling points (NBP) than the CFC. This is because when azeotropes do occur in these fluids, they are usually high pressure (i.e., low temperature) azeotropes. An acceptable drop-in candidate should have a vapor pressure as close as possible to that of the CFC to achieve a similar capacity in the same machine. Using these simple rules and the NIST-developed properties program REFPROP (Gallagher et al., 1991), it was possible to determine the candidate binaries and the compositions at which they form azeotropes.

As has been previously discussed, virtually all of the halogenated hydrocarbon azeotropic pairs have been identified, so it was decided to explore several halogenated hydrocarbon and hydrocarbon pairs to determine if any of their azeotropes can match the performance of the 
fluids slated for elimination. Since an azeotrope would be expected to have a higher pressure than either component, both components of an R-22 substitute should have normal boiling points above that of R-22. Further for an azeotrope to be likely, one component should be polar such as the HFCs and the other nonpolar such as the hydrocarbons. Since the hydrocarbons are all flammable, it was felt logical to select an HFC component that was nonflammable to have some hope of suppressing this undesirable characteristic. Hence, HFC-134a was chosen for one component for all mixtures because of its saturation pressure somewhat lower than R-22, its high polarity, and its nonflammability. Three hydrocarbons were selected as likely candidate fluids, propane (R-290), isobutane (R-600a), and cyclopropane (R-C270). Because of its higher cost and limited availability the only experimental work that was done with the R-134a/cyclopropane mixture was verification of its azeotrope and experimental measurement of its interaction coefficient. Sufficient quantities of the other mixtures were available to allow testing in a lowcharge laboratory breadboard heat pump apparatus and flammability testing in accordance with ASTM-E681.

\subsection{Verification of Azeotropes for Experimental Evaluation}

The Gibbs-Konowalow rule states that if an extremum exists in either the pressure vs. composition or the temperature vs. composition diagram for a mixture, then the dew and bubble lines will touch, and be tangent and an azeotrope will exist at that point.

The azeotropes in this study were verified by measuring the saturation pressures at known temperature and two-phase densities of compositions near the predicted azeotrope point. To do this an appropriate amount of each component to produce a two-phase mixture of the desired 
composition was introduced into a $25 \mathrm{cc}$ sample bottle, allowed to stabilize in a controlled temperature bath, and the pressure and temperature were recorded. Observation of a saturation pressure higher than either component would have had at the observed bath temperature confirmed the existence of an azeotrope by the Gibbs-Konowalow rule. Interaction coefficients were then regressed from this data and used in the property calculation program (Gallagher et al., 1991) and in cycle performance simulations.

We determined interaction coefficients for use in the NIST REFPROP refrigerant properties program to be 0.1542 for the $\mathrm{R}-134 \mathrm{a}$ /propane mixture, 0.1503 for the $\mathrm{R}$ 134a/isobutane mixture, and 0.1204 for the R-134a/cyclopropane mixture. Figures 5, 6 and 7 present bubble and dew point pressures with respect to composition for a each of these mixtures at three temperatures. These were computed using REFPROP with the interaction coefficients in each, a maximum in pressure for each constant temperature curve, i.e., a point higher in pressure than either of the two pure fluids of which the mixture is comprised, is observed. It is also observed that at the maximum, the point of azeotropic composition, the dew and bubble lines touch and are tangent.

For the temperature range of refrigerating, air conditioning, and heat pumping applications, the azeotropic point is approximately 45 percent propane by weight for the R134a/propane mixture. As the temperature increases, the azeotropic composition shifts to the lean R-290, i.e., rich HFC-134a direction, which means the azeotropic composition changes as the pressure or temperature changes. But the 45 percent propane mixture is regarded as a nearazeotrope (Didion and Bivens, 1990) for engineering applications.

Figure 6 shows the bubble and dew point pressures with respect to composition for the 
R-134a/isobutane mixture at three different temperatures, and each constant temperature curve displays a pressure maximum. For each temperature considered, the azeotropic composition is approximately 80 percent HFC-134a by weight. As the temperature increases, the azeotropic composition shifts to the rich HFC-134a direction.

Figure 7 shows the bubble and dew point pressures with respect to composition for the R-134a/cyclopropane mixture at three different temperatures and each constant temperature curve displays a pressure maximum. For each temperature considered, the azeotropic composition is approximately 65 percent HFC-134a by weight. As the temperature increases, the azeotropic composition shifts to the rich HFC-134a direction.

The saturation pressure curves of the refrigerants are shown in Figure 8. As indicated in the previous figures, these fluids form high-pressure azeotropes. The saturation pressure of R-290/134a is higher than that of either HCFC-22 or R-290, and the saturation pressure of R$134 \mathrm{a} / 600 \mathrm{a}$ is higher than that of CFC-12, HFC-134a, or R-600a. Theoretically, a higher saturation pressure implies a working fluid with a higher volumetric capacity. This trend was reflected in the test results (Figures 12 and 13).

\section{PERFORMANCE PREDICTION}

Prior to laboratory performance testing, cycle performances were simulated on the computer using the NIST developed CYCLE-11 (Domanski and McLinden, 1990). This computer model simulates a vapor compression cycle that takes the thermodynamic deviations from the ideal cycle into account. The simulated cycle is prescribed in terms of inlet and outlet temperatures of the external heat transfer fluids with the heat exchangers generalized by an 
average effective temperature difference. An isenthalpic expansion process is assumed. The program also includes a rudimentary model of a compressor and a representation of a liquidline/suction-line heat exchanger. Thermodynamic properties of the refrigerants are calculated using REFPROP (Gallagher et al., 1991). In section 5.4, Performance Simulation of Experimental Results, experimental data are used as input to CYCLE-11 to simulate cycle performance including compressor speed, pressure drops through heat exchangers, condenser subcooling, evaporator superheating, compressor polytropic efficiency, and overall compression efficiency. In this section, predictions in this section were made without experimental data on superheat, subcooling, or pressure drops as input. The purpose of these predictions is to suggest, by comparison, the likely performance of R-134a/cyclopropane for which no experimental cycle data were taken. In these simulations the evaporator and condenser pressure drops and respective superheat and subcooling were all assumed to be zero.

The simulations shown below for the three azeotropes as Table 1,2 and 3 were all performed for the DOE " $\mathrm{A}$ " high temperature cooling test condition. The conclusions from these predictions are that the propane/R-134a azeotrope is similar to R-22 in both capacity and efficiency, the cyclopropane/R-134a azeotrope has similar efficiency to R-22 but a 10 percent capacity loss, and the R-134a/isobutane azeotrope is more like $\mathrm{R}-12$ than $\mathrm{R}-22$. 
TABLE 1: Simulation results for propane/R-134a at the DOE " $\mathrm{A}$ " high temperature cooling test condition

\begin{tabular}{|c|c|c|c|}
\hline Refrigerant & HCFC-22 & $\begin{array}{r}\mathrm{HC}-290 / \mathrm{H} \\
(\mathrm{ma}\end{array}$ & $\begin{array}{l}\text { a }(45 / 55) \\
\text { on) }\end{array}$ \\
\hline LSHX & No & No & Yes \\
\hline EER/EER R-22 & 1.00 & 0.91 & 1.02 \\
\hline $\mathrm{Q}_{\mathrm{vol}} / \mathrm{Q}_{\mathrm{vol}} \mathrm{R}-22$ & 1.00 & 0.95 & 1.05 \\
\hline $\begin{array}{r}P_{\text {cond }}, \mathrm{kPa} \\
\text { (psia) }\end{array}$ & $\begin{array}{r}1648 \\
(239.0) \\
\end{array}$ & $\begin{array}{c}1513 \\
(266.0) \\
\end{array}$ & $\begin{array}{c}1472 \\
(257.5) \\
\end{array}$ \\
\hline $\begin{aligned} \mathrm{T}_{\mathrm{disc}},{ }^{\circ} \mathrm{C} \\
\left.\quad{ }^{\circ} \mathrm{F}\right)\end{aligned}$ & $\begin{array}{c}72.4 \\
(162.4)\end{array}$ & $\begin{array}{c}54.6 \\
(130.3)\end{array}$ & $\begin{array}{c}87.2 \\
(188.9)\end{array}$ \\
\hline
\end{tabular}

TABLE 2: Simulation results for R-134a/isobutane at the DOE " $\mathrm{A}$ " high temperature cooling test condition

\begin{tabular}{||l|c|c|c||}
\hline \multicolumn{1}{|c|}{ Refrigerant } & HCFC-22 & \multicolumn{2}{c|}{$\mathrm{R}-600 \mathrm{a} / \mathrm{HFC}-134 \mathrm{a}$ (20/80) } \\
\hline LSHX & No & No & Yes \\
\hline EER/EER R-22 & 1.00 & 0.96 & 1.07 \\
\hline $\mathrm{Q}_{\mathrm{vol}} / \mathrm{Q}_{\mathrm{vol}} \mathrm{R}-22$ & 1.00 & 0.68 & 0.75 \\
\hline $\mathrm{P}_{\text {cond }}, \mathrm{kPa}$ & 1648 & 1261 & 1221 \\
$(\mathrm{psia})$ & $(239.0)$ & $(182.9)$ & $(177.1)$ \\
\hline $\mathrm{T}_{\text {disc }},{ }^{\circ} \mathrm{C}$ & $\begin{array}{c}72.4 \\
(162.4)\end{array}$ & $\begin{array}{c}51.2 \\
(124.1)\end{array}$ & $\begin{array}{c}84.9 \\
(184.8)\end{array}$ \\
\hline
\end{tabular}


TABLE 3: Simulation results for R-134a/cyclopropane at the DOE "A" high temperature cooling test condition

\begin{tabular}{|c|c|c|c|}
\hline Refrigerant & HCFC-22 & \multicolumn{2}{|c|}{$\begin{array}{l}\mathrm{RC}-270 / \mathrm{HFC}-134 \mathrm{a}(35 / 65) \\
\text { (mass fraction) }\end{array}$} \\
\hline LSHX & No & No & Yes \\
\hline EER/EER R-22 & 1.00 & 0.99 & 1.04 \\
\hline $\mathrm{Q}_{\mathrm{vol}} / \mathrm{Q}_{\mathrm{vol}} \mathrm{R}-22$ & 1.00 & 0.87 & 0.91 \\
\hline $\begin{array}{r}P_{\text {cond }}, \mathrm{kPa} \\
\text { (psia) }\end{array}$ & $\begin{array}{c}1648 \\
(239.0)\end{array}$ & $\begin{array}{c}1513 \\
(219.4)\end{array}$ & $\begin{array}{c}1472 \\
(213.5)\end{array}$ \\
\hline $\mathrm{T}_{\text {disc }},{ }^{\circ} \mathrm{C}$ & $\begin{array}{c}72.4 \\
(162.4)\end{array}$ & $\begin{array}{c}60.7 \\
(141.2)\end{array}$ & $\begin{array}{c}94.2 \\
(201.6)\end{array}$ \\
\hline
\end{tabular}

\section{LABORATORY PERFORMANCE EVALUATION}

The experimental heat pump test setup was comprised of compressor, condenser, expansion device, and evaporator, as shown in Figure 9, and was described in detail by Pannock and Didion (1992). A reciprocating open compressor was driven by a variable-speed motor. A shaft torquemeter was installed between the compressor and the motor. The condenser and the evaporator were tube-in-tube, concentric type, counterflow heat exchangers. The refrigerant flowed inside the inner tube of the heat exchangers and a water/ethylene glycol mixture was pumped through the annulus. A manually adjusted needle valve expansion device was used in the system to control the flow rate of refrigerant and the pressure levels. A liquid-line/suctionline heat exchanger (LSHX) was installed so that the refrigerant could flow either to the expansion device directly or through this heat exchanger to the expansion device. The liquidline/suction-line heat exchanger was used to subcool the condensed liquid refrigerant by superheating the low temperature refrigerant vapor leaving the evaporator.

The refrigerant mixture composition was measured by extracting a small amount of vapor 
from the compressor discharge line during steady state operation. The sample was evaluated with a gas chromatograph.

\section{PERFORMANCE RESULTS AND DISCUSSION}

\subsection{High Temperature Cooling Test Results}

In these tests, the inlet temperature of the heat transfer fluid entering the condenser was maintained at $35.0^{\circ} \mathrm{C}$, and that entering the evaporator was kept at $26.7^{\circ} \mathrm{C}$. The outlet temperatures, chosen based on the previous experiment (Pannock and Didion, 1992), were $43.2^{\circ} \mathrm{C}$ and $14.4^{\circ} \mathrm{C}$, respectively. The operating conditions and test results are given in Table

5. The test results for all fluids are also presented in Figure 10 . The cooling capacity $\left(\dot{Q}_{\mathbf{r}}\right)$ is the amount of heat that is removed from the water/ethylene glycol stream within the evaporator per unit time. The cooling capacity was calculated by measuring the temperature difference across the evaporator and the mass flow rate of the secondary heat transfer fluid. The coefficient of performance (COP) is defined as the capacity $\left(\dot{Q}_{\mathrm{r}}\right)$ divided by the actual shaft work input to the compressor per unit time (i).

It is reasonable to categorize the fluids into two capacity groups for comparison, of which the first is HCFC-22 and its replacements, R-290 and R-290/134a, and the second is CFC-12 and its replacements, HFC-134a and R-134a/600a.

The cooling capacity of R-290/134a is greater than that of HCFC-22 or R-290 as would be expected of a higher pressure refrigerant. Similarly, the capacity of $\mathrm{R}-134 \mathrm{a} / 600 \mathrm{a}$ is greater than that of CFC-12 or HFC-134a. The coefficient of performance for R-290/134a is smaller 
than that for HCFC-22 and R-290. For R-134a/600a, the coefficient of performance is greater than that for CFC-12 and HFC-134a.

The discharge temperature and pressure are important factors because they influence lubricant life and system design. As shown in Table 5, the discharge temperature of R-290/134a is lower than that of HCFC-22 and slightly higher than R-290. R-134a/600a shows lower discharge temperature than CFC-12 and HFC-134a. Since the suction temperature is almost the same for all tests, the discharge temperature is largely a function of the specific heat of the vapor. For example, the specific heat of R-290/134a is larger than that of HCFC-22, so the discharge temperature is lower, which is a desirable condition.

The discharge pressure of R-290/134a is higher than that of HCFC-22 and R-290, and R-134a/600a shows slightly higher discharge pressure than CFC-12 and HFC-134a. Because the condensing temperature is almost the same for all tests, the discharge pressure is primarily related to saturation pressure (Figure 8). Because the saturation pressure of R-290/134a is higher than that of HCFC-22 and R-290, and that of R-134a/600a is higher than that of CFC-12 and HFC-134a, the discharge pressures are higher for these azeotropic mixtures. The discharge pressures for all cases were lower than the commercial design pressure limit of approximately $2.6 \mathrm{MPa}$.

\subsection{High Temperature Heating Test Results}

In these tests, the inlet temperature of heat transfer fluid into the condenser wass maintained at $21.1^{\circ} \mathrm{C}$ and that into the evaporator is kept at $8.3^{\circ} \mathrm{C}$. The outlet temperatures were determined by reversing the heat transfer fluid flow rates between the condenser and 
evaporator, that is, the evaporator flow rate for the cooling condition was the same as the condenser flow rate for the heating condition and vice versa. The main reason for doing this is that the flow rates of indoor and outdoor units in commercial heat pumps typically do not change when the operating mode (cooling or heating) is changed. Detailed test results are shown in Table 6.

The heating capacity $\left(\dot{\mathrm{Q}}_{\mathrm{h}}\right)$ of $\mathrm{R}-290 / 134 \mathrm{a}$ is greater than that of HCFC-22 and R-290, and the heating capacity of $\mathrm{R}-134 \mathrm{a} / 600 \mathrm{a}$ is greater than that of CFC-12 or HFC-134a, as is shown in Figure 11. The coefficient of performance for R-290/134a is lower than that for HCFC-22 and R-290, as is also shown in Figure 11. For R-134a/600a, the coefficient of performance is higher than that for CFC-12 and HFC-134a.

The discharge temperature shown in Table 6 presents a similar pattern to the cooling test condition. The discharge temperature of R-290/134a is lower than that for HCFC-22 and slightly higher than that for R-290. The discharge temperature of $\mathrm{R}-134 \mathrm{a} / 600 \mathrm{a}$ is lower than that of CFC-12 and HFC-134a. Because the suction temperatures are almost the same for all tests of the same test condition, a higher discharge temperature is obtained for refrigerants with the lower vapor specific heats.

The discharge pressure of R-290/134a is higher than that of HCFC-22 and R-290, and that of R-134a/600a is slightly higher than that of CFC-12 and HFC-134a, as shown in Table 6. All the discharge pressures of this test condition are lower than those of the high temperature cooling tests. 


\subsection{Liquid-Line/Suction-Line Heat Exchange}

The high temperature cooling and heating test results with liquid-line/suction-line heat exchange (LSHX) are shown in Figures 10 and 11. The LSHX subcools the liquid from the condenser with the suction vapor from the evaporator. The benefit of LSHX depends on both operating conditions and refrigerant properties (Domanski et al., 1992); it is an advantage when the vapor molar heat capacity is high and the lost work of expansion is comparatively large. All the test conditions with LSHX are maintained the same as the during the tests without LSHX.

The application of LSHX increases capacity in both high temperature cooling and heating tests, but the magnitude of the increase is different for the different fluids in this study. For the $\mathrm{R}-290 / 134 \mathrm{a}$ mixture, the vapor heat capacity is greater than that of HCFC-22 or R-290; thus the increase in cooling or heating capacity is greater than that of HCFC-22 or R-290 at both test conditions. Similarly, for R-134a/600a, which has a greater vapor heat capacity than CFC-12 and HFC-134a, the capacity increase at the high temperature cooling and heating condition is greater than that of CFC-12 or HFC-134a. The COP increase of R-290/134a is greater than that of HCFC-22 or R-290 for both the high temperature cooling and heating test. For the R134a/600a mixture, the increase in COP is significant compared with CFC-12 and HFC-134a.

The COP increase with respect to specific heat of the saturated vapor at constant pressure is shown in Figure 12. As shown in Figure 12, COP increase is almost proportional to the specific heat of the vapor phase, which corresponds with the simulated result in the reference (Domanski et al., 1992).

The discharge temperature is higher for all tests with LSHX, which was expected when any refrigerant's superheat is increased. The results show that the highest discharge temperature 
is obtained for HCFC-22 in every case, which is a result of its having the lowest vapor heat capacity. The discharge temperatures for other refrigerants are lower than that of HCFC-22 because they are more complex molecules and, therefore, have a higher heat capacity. The discharge pressure is almost the same for all tests with LSHX as for those without LSHX. As shown in Tables 5 and 6 , the average difference between the two cases is less than $2.5 \%$ for all test conditions.

\subsection{Performance Simulation of Experimental Results}

Experimental data were used to simulate cycle performance including compressor speed, pressure drops through heat exchangers, condenser subcooling, evaporator superheating, compressor polytropic efficiency, and overall compression efficiency. The tempertures of the heat transfer fluid entering and exiting the heat exchangers were taken from Table 4.

The predicted coefficient of performance with respect to volumetric capacity at the high temperature cooling condition is shown in Figure 13 and that at the high temperature heating condition is presented in Figure 14. Assuming that volumetric flow rates for different refrigerants are almost the same in the constant compressor speed test, the simulated volumetric capacity corresponds to the capacity in the experiment. Compared with the experimental results of Figures 10 and 11, the capacities and the coefficients of performance are well predicted by CYCLE-11. The simulated results for the cases using a liquid-line/suction-line heat exchanger show a similar pattern. Compared with the pure refrigerants, the azeotropes in this study produce comparable volumetric capacity. The coefficient of performance for R-290/134a is predicted slightly lower than that of HCFC-22 and the COP of R-134a/600a is higher than that 
of CFC-12 or HFC-134a when LSHX is not used. By applying LSHX, slightly higher volumetric capacities and COPs are predicted.

Tests for this study have been performed using a constant compressor speed criterion instead of the constant heat flux criterion used in most previous NIST heat pump studies. In a practical sense, the constant compressor speed test answers the question of drop-in performance change in a system as a result of changing only the refrigerant. Typically, constant heat flux tests are performed with the capacity maintained constant by varying the compressor speed; hence they evaluate the effect on system performance of two component changes; refrigerant and compressor speed. Constant compressor speed tests overstate the efficiency of low volumetric capacity refrigerants as a result of lower heat fluxes and commensurately reduced refrigerant-toheat sink temperature differences. Constant heat flux tests tend to understate the efficiency of low volumetric capacity refrigerants as a result of increased refrigerant pressure drop (particularly on the low pressure side) with increased compressor speed. The comparisons in this study are made in two capacity groups, one near CFC-12 and the other near HCFC-22. It is felt that the capacity range in each group is sufficiently small that test results by either criterion would be comparable since the two test criteria are identical when comparing refrigerants of identical volumetric capacity. However, in interpreting the results it is well to be alert to this bias in favor of low capacity refrigerants when comparisons are made among more widely disparate refrigerants.

A final point should be made regarding the R-290 test results relative to HCFC-22. Although the coefficient of performance of R-290 is less than that of HCFC-22 in a simplified computer simulation, the laboratory tests in this study show the opposite results. We should note 
that all of the tests were conducted with the constant compressor speed criterion. The capacity of R-290 is lower than that of HCFC-22; thus the heat exchanger loading decreases and so does the average temperature difference in the heat exchanger. The liquid viscosity of R-290 is approximately $65 \%$ and the vapor density is approximately $41 \%$ of HCFC- 22 in the test range, so R-290 has a significantly smaller pressure drop (about half of HCFC-22) in the heat exchangers and the liquid thermal conductivity of R-290 is approximately $10 \%$ higher than that of HCFC-22. Therefore, the overall heat transfer coefficient for R-290 is higher than that for R-22 and the effective average temperature difference in the heat exchanger for R-290 is lower. These factors result in higher COP values than the simplified simulation results.

Although system performance is influenced by design optimization for a specific working fluid, the tests were conducted in the same test rig and the same test conditions. Therefore a different system may give slightly different results, but the major conclusions will not change.

\section{FLAMMABILITY MEASUREMENTS}

Flammability tests were performed to determine the flammability limits of the azeotropic mixtures in this study. The flammability test apparatus is described in ASTM-681 (ASTM, 1992). It is desirable that refrigerants be nonflammable; however, recent studies suggest that pure propane (R-290) has several merits as a refrigerant (Kramer, 1991) and, of course, ammonia has been widely used in industrial applications throughout the history of refrigeration. Investigations into the use of propane in domestic refrigerators have included energy consumption tests, combustion tests, fire tests, etc. (James and Missenden, 1992). The conclusion is that a refrigerator with propane is capable of similar performance to one with 
CFC-12 without design changes, and the explosion and fire risks are small. Many industrial applications of heat pumps have traditionally used hydrocarbons as refrigerants particularly where other flammable materials are present and experienced personnel are available. Nevertheless a minimization of flammability is always desirable with all other characteristics being equal.

The main concept of our study of flammability is to add nonflammable HFC-134a to flammable hydrocarbons to reduce the flammability of the hydrocarbon and retain the thermodynamic and practical advantages of the current single-component CFC. In this study, the compositions of the mixtures were sought out so as to have azeotropic behavior and the flammability tests are done for those specific compositions.

The flammability limits were determined by visual observation of all the recorded flammability tests on video tapes. In this study, the flammability limits of flammable mixtures are represented by the composition range where the flame propagates horizontally outward from the ignition source after being mixed with air and ignited. The flammability limits of R$290 / 134$ a ( $45 / 55$ by mass percentage) are found to be $2.9-11.0 \%$ by volume in a refrigerant/air mixture. Those of $R-134 \mathrm{a} / 600 \mathrm{a}$ ( $80 / 20$ by mass percentage) are $3.9-13.3 \%$ by volume in a refrigerant/air mixture. These results may be compared to the results for pure hydrocarbons $\mathrm{R}$ 290 and R-600a, where the limits are $2.1-9.6 \%$ and $1.7-9.7 \%$ by volume respectively (Richard and Shankland, 1992). It is noteworthy that the lower limit is higher for both mixtures than that for pure hydrocarbons. Although the azeotropic mixtures remain flammable, they are less flammable than their pure hydrocarbon compounds. It is well-known that the presence of a halogen compound may show flame inhibition characteristics (Biordi et al., 1973; Ho et al., 
1992). While suppressing flammability, a drawback to the addition of halogen compounds is their tendency to produce toxic combustion products.

The heat of combustion can be calculated if the chemical equations describing the combustion process are known. Unfortunately, the combustion processes of HFC refrigerants are seldom known, and it was therefore difficult to predict the final combustion products in this study. But from the chemical features of the refrigerant mixture and the visual observation of flame propagation and flame intensity in this study, the released heat of combustion of the mixture seems less than that of pure hydrocarbons.

\section{CONCLUDING REMARKS}

In this paper, heat pump performance tests were conducted for two azeotropic refrigerant mixtures of HFC-134a (1,1,1,2-tetrafluoroethane) with R-290 (Propane) and R-600a (Isobutane): $\mathrm{R}-290 / 134 \mathrm{a}$ ( $45 / 55$ by mass percentage) and $\mathrm{R}-134 \mathrm{a} / 600 \mathrm{a}(80 / 20$ by mass percentage). The performance characteristics of R-290/134a were compared with those of pure HCFC-22 and R290, and those of R-134a/600a were compared with those of CFC-12 and HFC-134a at the high temperature cooling and heating test conditions including those cases using liquid-line/suctionline heat exchange.

The cooling or heating capacity of R-290/134a is greater than that of HCFC-22 and R290. The capacity of $\mathrm{R}-134 \mathrm{a} / 600 \mathrm{a}$ is also greater than that of CFC-12 or HFC-134a. The coefficient of performance for R-290/134a is lower than that for HCFC-22 and R-290, and R134a/600a shows higher COP than CFC-12 and HFC-134a. Results show that the discharge temperature of R-290/134a is lower than that of HCFC-22 and slightly higher than that of R- 
290. The discharge temperature of R-134a/600a is lower than that of CFC-12 and HFC-134a. R-290/134a mixture has a higher discharge pressure than HCFC-22 and R-290, and R-134a/600a has a slightly higher discharge pressure than CFC-12 and HFC-134a.

Even though the coefficient of performance of R-290/134a is slightly lower than that of HCFC-22 and R-290, because of its greater capacity and reduced flammability compared with $\mathrm{R}-290, \mathrm{R}-290 / 134 \mathrm{a}$ can be a possible substitute for HCFC-22. Regarding the R-134a/600a mixture, it can be a possible substitute for CFC- 12 because of its higher capacity and coefficient of performance. A patentability search for the R-134a/R-290 and R-134a/R-600a azeotropes revealed a research disclosure (Du Pont, 1977) describing azeotropes of R-134a with propane, isobutane, and n-butane, useful as propellants and refrigerants (no data). Hence no patents were pursued for these azeotropic mixtures.

Although no experimental performance evaluations were performed, computer simulations indicate that the azeotrope of $\mathrm{R}-134 \mathrm{a}$ with $\mathrm{H}-\mathrm{C} 270$ would also be a possible $\mathrm{R}-22$ substitute, albeit one resulting in a capacity loss of approximately 10 percent.

The simulation results generally agreed with the experimental observations, but complete agreement required introduction of the experimentally observed system pressure drops as input to the model simulations because of the extreme variation in vapor density and viscosity in the studied fluids.

None of the azeotropes studied could be considered perfect replacements for R-22 because of their flammability. An additional concern with strong azeotropes such as these is the narrow band with respect to composition, temperature, and pressure in which the azeotrope exists. Outside of this band the two-phase temperature glide rapidly exceeds values typical of 
fluids described as near azeotropes.

It appears that there are no binary azeotropes that can be directly substituted for R-22 in the majority of applications. Hence, it is felt that future work should be directed at near azeotropes for this application. It should be noted that many near azeotropes act more like azeotropes than do mixtures which exhibit strong true azeotropes but are operated at temperatures or compositions away from their azeotrope point. Near azeotropes to be considered would also include mixtures which form weak true azeotropes since these do not exhibit the sensitivity to conditions seen in strong azeotropes. 


\section{NOMENCLATURE}

$\begin{array}{ll}\text { COP } & \text { coefficient of performance } \\ \text { L3HX } & \text { liquid-line/suction-line heat exchanger } \\ \mathrm{P} & \text { pressure }[\mathrm{MPa}] \\ \mathrm{Q} & \text { capacity } \\ \dot{\mathrm{Q}} & \text { transferred heat per unit time }[\mathrm{W}] \\ \mathrm{T} & \text { temperature }\left[{ }^{\circ} \mathrm{C}\right] \\ \dot{\mathrm{W}} & \text { compressor power }[\mathrm{W}]\end{array}$

Subscript

$\begin{array}{ll}\text { cond } & \text { condenser } \\ \text { disc } & \text { discharge } \\ \text { h } & \text { heat pumping } \\ \text { r } & \text { refrigeration } \\ \text { vol } & \text { volumetric }\end{array}$




\section{ACKNOWLEDGEMENT}

The authors would like to thank Mr. Terry G. Statt, Project Manager of Electric Power Research Institute (RP 8013-03, RP 2033-8 and RP 2792-9), for his financial support and patience and the Korea Science and Engineering Foundation (KOSEF) for its financial support

of M. S. Kim's stay at NIST. The authors would also like to thank Dr. Piotr Domanski of NIST for his continuing helpful comments and interactions. 


\section{REFERENCES}

ASHRAE, 1983, Methods of Testing for Seasonal Efficiency of Unitary Air-Conditioners and Heat Pumps, ASHRAE Standard, ANSI/ASHRAE 116-1983.

ASTM, 1992, Standard Test Method for Concentration Limits of Flammability of Chemicals, 1992 Annual Book of ASTM Standards, Vol. 14.02, pp. 484-490.

Biordi, J. C., Lazzara, C. P., and Papp, J. F., 1973, Flame-Structure Studies $\mathrm{CH}_{3} \mathrm{Br}$ Inhibited Methane Flames, Fourteenth Symposium (International) on Combustion, pp. 367-381.

Didion, D. A. and Bivens, D. B., 1990, Role of Refrigerant Mixtures as Alternatives to CFCs, Int. J. Refrig., Vol. 13, pp. 163-175.

Domanski, P. A. and Didion, D. A., 1993, Thermodynamic Evaluation of R-22 Alternative Refrigerants and Refrigerant Mixtures, ASHRAE Trans., Vol. 99, Pt. 2, Paper No. DE-93-6-2.

Domanski, P. A., Didion, D. A., and Doyle, J. P., 1992, Evaluation of Suction Line Liquid Line Heat Exchange in the Refrigeration Cycle, Proc. of the 1992 International Refrigeration Conf., Purdue Univ., West Lafayette, IN, U.S.A., Vol. 1, pp. 131-139.

Domanski, P. A. and McLinden, M. O., 1990, A Simplified Cycle Simulation Model for the Performance Rating of Refrigerants and Refrigerant Mixtures, Proc. of ASHRAEPurdue CFC Conf., Purdue Univ., West Lafayette, IN, U.S.A., pp. 466-475.

Downing, R.C., Fluorocarbon Refrigerants Handbook (1988), Prentice- Hall, Englewood Cliffs, NJ, 143-144.

Du Pont de Nemours and Co., Inc., Anon., Res. Discl. 1977, 162, 70 cited as 87:200710q in Chemical Abstracts, Vol. 87, 1977.

Gallagher, J., McLinden, M. O., Morrison, G., Huber, M., and Ely, J., 1991, NIST Thermodynamic Properties of Refrigerants and Refrigerant Mixtures, Ver. 3.03, NIST Standard Reference Database 23, National Institute of Standards and Technology, Gaithersburg, MD, U.S.A.

Ho, W.-P., Barat, R. B., and Bozzelli, J. W., 1992, Thermal Reactions of $\mathrm{CH}_{2} \mathrm{Cl}_{2}$ in $\mathrm{H}_{2} / \mathrm{O}_{2}$ Mixtures: Implication for Chlorine Inhibition of $\mathrm{CO}$ conversion to $\mathrm{CO}_{2}$, Comb. and Flame, Vol. 88, pp. 265-295.

Horsley, L.H., Azeotropic Data, v1.,Advances in Chemistry Series, no. 6 (1952); v2., Advances in Chemistry Series, no. 35 (1962); v3., Advances in Chemistry Series, no. 116 (1973), American Chemical Society, Washington, DC. 
James, R. W. and Missenden, J. F., 1992, The Use of Propane in Domestic Refrigerators, Int. J. Refrig., Vol. 15, No. 2, pp. 95-98.

Kramer, D., 1991, Why Not Propane?, ASHRAE J., Vol. 33, No. 6, pp. 52-55.

McLinden, M. O. and Didion, D. A., 1987, CFC's: Is the Sky Falling? Quest for Alternatives, ASHRAE J., Vol 29, No. 12, pp. 32-42.

Meyer, C.W. and Morrison, G., Dipole Moments of Seven Partially Halogenated Ethane Refrigerants, J. Phys. Chem. (1991) 95, 3860-3866.

Morrison, G. and McLinden, M., 1993, Azeotropy in Refrigerant Mixtures, Int. J. Refrig., Vol. 16, pp. 129-138.

Pannock, J. and Didion, D. A., 1992, The Performance of Chlorine-Free Binary Zeotropic Refrigerant Mixtures in a Heat Pump, NISTIR 4748, National Institute of Standards and Technology, Gaithersburg, MD, U.S.A.

Pesuit, D.R., Binary interaction constants for mixtures with a wide range in component properties, Ind. Eng. Chem. Fundam. (1978) 17, 235-242.

Richard, R. G. and Shankland, I. R., 1992, Flammability of Alternate Refrigerants, ASHRAE J., Vol. 34, No. 4, pp. 20-24. 
FIGURE LIST

Figure 1 The values of $f_{12}$ that will produce a positive pressure deviation azeotrope at the normal boiling point of the more volatile component of 300 binary mixtures.

Figure 2 The values of $f_{12}$ plotted into a space defined by the ratio of the dipole moment divided by the excluded molecular volume consistent with the equation of state, $\mu / b$, for the mixture.

Figure 3 The value of $f_{12}$ estimated for 300 refrigerant mixtures. Grid points marked with a $B$ indicate a Bancroft point.

Figure $4 \quad$ Binary mixtures that would have azeotropes by comparing Figures 1 and 3.

Figure 5 Pressure with respect to composition diagram of the R-290/134a mixture.

Figure 6 Pressure with respect to composition diagram of the R-134a/600a mixture.

Figure 7 Pressure with respect to composition diagram of the R-134a/R-C270 mixture.

Figure $8 \quad$ Saturation pressure curves for several refrigerants.

Figure 9 Schematic diagram of the mini breadboard heat pump test rig.

Figure 10 Cooling COP with respect to cooling capacity at the high temperature cooling condition (by experiment).

Figure 11 Heating COP with respect to heating capacity at the high temperature heating condition (by experiment).

Figure 12 COP increase versus specific heat of saturated vapor at constant pressure when liquid line/suction line heat exchange is applied.

Figure 13 Simulated cooling COP with respect to volumetric capacity at the high temperature cooling condition.

Figure 14 Simulated heating COP with respect to volumetric capacity at the high temperature heating condition. 


\section{TABLE LIST}

Table 1 Predictive simulation for R-134a/propane at the DOE "A" high temperature cooling test condition.

Table 2 Predictive simulation for R-134a/isobutane at the DOE "A" high temperature cooling test condition.

Table 3 Predictive simulation for R-134a/cyclopropane at the DOE "A" high temperature cooling test condition.

Table 4 High temperature cooling and heating conditions.

Table 5 NIST mini-breadboard heat pump test results (high temperature cooling condition).

Table 6 NIST mini-breadboard heat pump test results (high temperature heating condition). 
Table 4: High temperature cooling and heating conditions

\begin{tabular}{lcc}
\hline Position & $\begin{array}{l}\text { High Temperature } \\
\text { Cooling Condition }\left({ }^{\circ} \mathrm{C}\right)\end{array}$ & $\begin{array}{l}\text { High Temperature } \\
\text { Heating Condition }\left({ }^{\circ} \mathrm{C}\right)\end{array}$ \\
\hline Condenser Inlet & 35.0 & 21.1 \\
Condenser Outlet & $43.2^{*}$ & VFRE \\
Evaporator Inlet & 26.7 & 8.3 \\
Evaporator Outlet & $14.4^{*}$ & VFRC \\
\hline
\end{tabular}

VFRC : Volume flow rate of heat transfer fluid in condenser VFRE : Volume flow rate of heat transfer fluid in evaporator * : Selected value 
25: NIST mini-breadboard heat pump test results for high temperature cooling condition

\begin{tabular}{|c|c|c|c|c|c|c|}
\hline \multirow{2}{*}{$\begin{array}{l}\text { rigerant } \\
\mathrm{IX}\end{array}$} & \multicolumn{2}{|c|}{ HCFC-22 } & \multicolumn{2}{|c|}{$\mathrm{R}-290$} & \multicolumn{2}{|c|}{$\mathrm{R}-290 / 134 \mathrm{a}$} \\
\hline & No & YES & No & YES & No & YES \\
\hline nposition & & & & & $44.1 / 55.9$ & $43.2 / 56$ \\
\hline Iling COP & 4.733 & 4.786 & 5.130 & 5.277 & 4.425 & 4. \\
\hline ling capacity, W & 2743.3 & 2799.3 & 2469.2 & 2582.7 & 2757.3 & 2926. \\
\hline npressor speed, rpm & 1000.2 & 1000.4 & 1001.0 & 1000.2 & 1000.2 & ك \\
\hline npressor power, $W$ & 579.6 & 584.9 & 481.3 & 489.4 & 623.1 & 620.5 \\
\hline p. HTF inlet $\mathrm{T},{ }^{\circ} \mathrm{C}$ & 26.7 & 26.7 & 26.7 & 26.7 & 26.7 & 26. \\
\hline p. HTF outlet $\mathrm{T},{ }^{\circ} \mathrm{C}$ & 14.4 & 14.4 & 14.4 & 14.4 & 14.4 & 14.4 \\
\hline d. HTF inlet $\mathrm{T},{ }^{\circ} \mathrm{C}$ & 35.0 & 35.1 & 35.0 & 35.0 & 35.0 & $35 .($ \\
\hline d. HTF outlet $\mathrm{T},{ }^{\circ} \mathrm{C}$ & 43.2 & 43.2 & 43.2 & 43.3 & 43.1 & 43.2 \\
\hline .p. suction $\mathrm{P}$, bar & 6.72 & 6.74 & 6.59 & 6.61 & 7.84 & $7 . \varepsilon$ \\
\hline ap. discharge $\mathrm{P}, \mathrm{bar}$ & 17.34 & 17.39 & 15.49 & 15.35 & 19.15 & $18 . \subseteq$ \\
\hline 'harge P/Suction $\mathrm{P}$ & 2.581 & 2.578 & 2.351 & 2.321 & 2.443 & 2.4 \\
\hline ip. discharge $\mathrm{T},{ }^{\circ} \mathrm{C}$ & 79.9 & 89.6 & 64.0 & 73.2 & 65.4 & 73.5 \\
\hline d. subcooling, ${ }^{\circ} \mathrm{C}$ & 2.1 & 2.3 & 2.7 & 2.5 & 2.4 & 2.2 \\
\hline p. superheat, ${ }^{\circ} \mathrm{C}$ & 14.3 & 14.6 & 13.4 & 13.6 & 14.1 & 14. $C$ \\
\hline p. P drop, bar & 0.47 & 0.39 & 0.18 & 0.26 & 0.38 & 0.4 \\
\hline d. P drop, bar & 0.53 & 0.48 & 0.28 & 0.25 & 0.49 & 0.4 \\
\hline
\end{tabular}




\begin{tabular}{|c|c|c|c|c|c|c|}
\hline \multirow{2}{*}{$\begin{array}{l}\text { igerant } \\
\mathrm{XX}\end{array}$} & \multicolumn{2}{|c|}{ CFC-12 } & \multicolumn{2}{|c|}{ HFC-134a } & \multicolumn{2}{|c|}{$\mathrm{R}-134 \mathrm{a} / 600 \mathrm{a}$} \\
\hline & No & YES & No & YES & NO & YES \\
\hline iposition & & & & & $81.1 / 18.9$ & $82.4 / 17$ \\
\hline ling $C O P$ & 4.259 & 4.533 & 4.369 & 4.690 & 4.406 & 4.7 \\
\hline ling capacity, w & 1657.0 & 1755.0 & 1807.7 & 1899.7 & 1926.1 & 2078.1 \\
\hline ıpressor speed, rpm & 1006.2 & 1003.6 & 1002.2 & 1001.1 & 1002.5 & 1000.6 \\
\hline Ipressor power, W & 389.1 & 387.2 & 413.8 & 405.0 & 437.2 & 437.7 \\
\hline ?. HTF inlet $\mathrm{T},{ }^{\circ} \mathrm{C}$ & 26.7 & 26.7 & 26.7 & 26.7 & 26.7 & 26.7 \\
\hline ?. HTF outlet $\mathrm{T},{ }^{\circ} \mathrm{C}$ & 14.3 & 14.4 & 14.4 & 14.4 & 14.3 & 14.4 \\
\hline d. HTF inlet $\mathrm{T},{ }^{\circ} \mathrm{C}$ & 35.1 & 35.0 & 35.0 & 35.0 & 35.0 & 35.0 \\
\hline d. HTF outlet $\mathrm{T},{ }^{\circ} \mathrm{C}$ & 43.3 & 43.2 & 43.2 & 43.2 & 43.1 & 43.2 \\
\hline ip. suction $\mathrm{P}$, bar & 4.16 & 4.20 & 4.11 & 4.14 & 4.88 & 4.8 \\
\hline ıp. discharge $\mathrm{P}$, bar & 10.97 & 10.97 & 11.44 & 11.38 & 12.69 & 12.8 \\
\hline harge P/Suction $\mathrm{P}$ & 2.637 & 2.610 & 2.785 & 2.751 & 2.601 & 2.6 \\
\hline Ip. discharge $\mathrm{T},{ }^{\circ} \mathrm{C}$ & 67.7 & 78.3 & 65.2 & 73.0 & 61.6 & 70.5 \\
\hline d. subcooling, ${ }^{\circ} \mathrm{C}$ & 1.7 & 3.0 & 2.0 & 3.4 & 2.5 & 2.3 \\
\hline ?. superheat, ${ }^{\circ} \mathrm{C}$ & 13.2 & 13.2 & 13.7 & 13.8 & 12.7 & 12.9 \\
\hline ?. P drop, bar & 0.32 & 0.30 & 0.32 & 0.31 & 0.31 & 0.4 \\
\hline d. P drop, bar & 0.38 & 0.37 & 0.36 & 0.31 & 0.39 & 0.3 \\
\hline
\end{tabular}


26: NIST mini-breadboard heat pump test results (high temperature heating condition)

\begin{tabular}{|c|c|c|c|c|c|c|}
\hline \multirow{2}{*}{$\begin{array}{l}\text { rigerant } \\
\text { IX }\end{array}$} & \multicolumn{2}{|c|}{ HCFC-22 } & \multicolumn{2}{|c|}{$\mathrm{R}-290$} & \multicolumn{2}{|c|}{$\mathrm{R}-290 / 134 \mathrm{a}$} \\
\hline & NO & YES & NO & YES & NO & YES \\
\hline nposition & & & & & $44.3 / 55.7$ & $44.0 / 56$ \\
\hline ting COP & 5.335 & 5.414 & 5.625 & 5.825 & 5.100 & 5.8 \\
\hline ting capacity, W & 2404.1 & 2406.8 & 2168.7 & 2226.7 & 2482.4 & $2572 . \mathrm{C}$ \\
\hline npressor speed, rpm & 1001.5 & 1000.5 & 1000.7 & 1000.5 & 1000.3 & 1001.2 \\
\hline npressor power, W & 450.6 & 444.6 & 385.6 & 382.3 & 486.7 & 481.5 \\
\hline p. HTF inlet $\mathrm{T},{ }^{\circ} \mathrm{C}$ & 8.3 & 8.3 & 8.3 & 8.3 & 8.3 & 8.2 \\
\hline p. HTF outlet $\mathrm{T},{ }^{\circ} \mathrm{C}$ & 3.1 & 3.0 & 3.0 & 2.9 & 3.1 & 2.5 \\
\hline d. HTF inlet $\mathrm{T},{ }^{\circ} \mathrm{C}$ & 21.1 & 21.1 & 21.1 & 21.1 & 21.1 & 21.1 \\
\hline d. HTF outlet $\mathrm{T},{ }^{\circ} \mathrm{C}$ & 31.9 & 31.7 & 31.9 & 31.7 & 32.2 & 31.5 \\
\hline ap. suction $\mathrm{P}$, bar & 4.76 & 4.78 & 4.73 & 4.74 & 5.63 & 5.6 \\
\hline ip. discharge $P$, bar & 12.90 & 12.74 & 11.61 & 11.48 & 14.58 & 14.1 \\
\hline 'harge P/Suction P & 2.710 & 2.663 & 2.455 & 2.420 & 2.588 & 2.5 \\
\hline up. discharge $\mathrm{T},{ }^{\circ} \mathrm{C}$ & 68.9 & 78.2 & 52.8 & 63.4 & 52.2 & 63.1 \\
\hline d. subcooling, ${ }^{\circ} \mathrm{C}$ & 2.3 & 2.3 & 2.8 & 2.8 & 2.9 & 2.5 \\
\hline p. superheat, ${ }^{\circ} \mathrm{C}$ & 8.4 & 8.3 & 7.9 & 7.9 & 8.2 & 8.4 \\
\hline p. P drop, bar & 0.35 & 0.33 & 0.25 & 0.24 & 0.31 & 0.3 \\
\hline d. P drop, bar & 0.37 & 0.30 & 0.19 & 0.17 & 0.34 & 0.3 \\
\hline
\end{tabular}




\begin{tabular}{|c|c|c|c|c|c|c|}
\hline \multirow{2}{*}{$\frac{\text { igerant }}{\mathrm{X}}$} & \multicolumn{2}{|c|}{$\mathrm{CFC}-12$} & \multicolumn{2}{|c|}{ HFC-134a } & \multicolumn{2}{|c|}{$\mathrm{R}-134 \mathrm{a} / 600 \mathrm{a}$} \\
\hline & No & YES & NO & YES & NO & YES \\
\hline Iposition & & & & & $81.2 / 18.8$ & $81.5 / 18$ \\
\hline ting $\mathrm{COP}$ & 4.755 & 5.004 & 4.844 & 5.114 & 4.972 & 5.3 \\
\hline ting capacity, $\mathrm{W}$ & 1464.6 & 1514.1 & 1556.1 & 1570.7 & 1697.1 & 1746.9 \\
\hline ıpressor speed, rpm & 1003.3 & 1003.3 & 1002.0 & 1002.5 & 1001.9 & 1000.8 \\
\hline Ipressor power, W & 308.0 & 302.6 & 321.2 & 307.2 & 341.3 & 328.7 \\
\hline ?. HTF inlet $\mathrm{T},{ }^{\circ} \mathrm{C}$ & 8.3 & 8.3 & 8.3 & 8.3 & 8.3 & 8.3 \\
\hline ?. HTF outlet $\mathrm{T},{ }^{\circ} \mathrm{C}$ & 3.0 & 3.2 & 3.2 & 3.0 & 3.2 & 3.0 \\
\hline d. HTF inlet $\mathrm{T},{ }^{\circ} \mathrm{C}$ & 21.1 & 21.1 & 21.1 & 21.1 & 21.1 & 21.1 \\
\hline d. HTF outlet $\mathrm{T},{ }^{\circ} \mathrm{C}$ & 31.9 & 31.8 & 31.8 & 31.3 & 32.0 & 31.5 \\
\hline Ip. suction $P$, bar & 2.94 & 2.98 & 2.82 & 2.83 & 3.43 & 3.4 \\
\hline Ip. discharge $P$, bar & 7.99 & 8.00 & 8.16 & 8.11 & 9.39 & 9.2 \\
\hline harge $\mathrm{P} /$ suction $\mathrm{P}$ & 2.714 & 2.683 & 2.899 & 2.867 & 2.738 & 2.7 \\
\hline lp. discharge $\mathrm{T},{ }^{\circ} \mathrm{C}$ & 58.4 & 68.6 & 54.8 & 62.5 & 50.9 & 59.7 \\
\hline d. subcooling, ${ }^{\circ} \mathrm{C}$ & 4.1 & 4.6 & 3.1 & 2.1 & 3.8 & 2.5 \\
\hline ?. superheat, ${ }^{\circ} \mathrm{C}$ & 8.4 & 8.1 & 8.0 & 7.9 & 7.7 & 7.8 \\
\hline ?. P drop, bar & 0.25 & 0.23 & 0.26 & 0.25 & 0.23 & 0.2 \\
\hline d. $P$ drop, bar & 0.28 & 0.27 & 0.21 & 0.20 & 0.27 & 0.2 \\
\hline
\end{tabular}




\section{Appendix A Uncertainty Analysis}

I Evaporator Uncertainty

$$
\dot{Q}_{E}=\dot{m} c_{p} \Delta T
$$

where :

$\dot{Q}_{E}$ : evaporator capacity (W)

$\dot{m}$ : mass flow rate of heat transfer fluid through the evaporator $(\mathrm{kg} / \mathrm{s})$

$c_{p}$ : specific heat of heat transfer fluid $\left(\mathrm{J} / \mathrm{kg}{ }^{\circ} \mathrm{C}\right)$

$\Delta T$ : magnitude of the heat transfer fluid temperature change through the heat exchanger $\left({ }^{\circ} \mathrm{C}\right)$

Based on an RMS uncertainty propagation analysis:

$$
w_{\dot{Q}_{E}}=\left[\left(\frac{\partial \dot{Q}_{E}}{\partial \dot{m}} w_{\dot{m}}\right)^{2}+\left(\frac{\partial \dot{Q}_{E}}{\partial c_{p}} w_{c_{p}}\right)^{2}+\left(\frac{\partial \dot{Q}_{E}}{\partial \Delta T} w_{\Delta T}\right)^{2}\right]^{\frac{1}{2}}
$$

where $w_{i}$ is the uncertainty in the $i$ th parameter.

From (1):

$$
\begin{aligned}
& \frac{\partial \dot{Q}_{E}}{\partial \dot{m}}=c_{p} \Delta T \\
& \frac{\partial \dot{Q}_{E}}{\partial c_{p}}=\dot{m} \Delta T \\
& \frac{\partial \dot{Q}_{E}}{\partial \Delta T}=\dot{m} c_{p}
\end{aligned}
$$

Substituting Eqn. 3 into Eqn. 2 gives 


$$
w_{\dot{Q}_{E}}=\left[\left(c_{p} \Delta T w_{\dot{m}}\right)^{2}+\left(\dot{m} \Delta T w_{c_{p}}\right)^{2}+\left(\dot{m} c_{p} w_{\Delta T}\right)^{2}\right]^{\frac{1}{2}}
$$

It remains now to estimate $w_{\dot{m}}, w_{c_{p}}, w_{\Delta T}$

Sample Calculation (using data from a heat pump test)

\section{A. Estimate $w_{m}$}

Based on the manufacturers (Micro Motion Inc.) stated accuracy of its model B25 mass flow meter:

$$
w_{\dot{m}}= \pm 0.4 \% \text { of flowrate }
$$

In this example: $\dot{m}=0.0894 \mathrm{~kg} / \mathrm{s} \therefore$

$$
w_{\dot{m}}=3.58 \times 10^{-4} \mathrm{~kg} / \mathrm{s}
$$

\section{B. Estimate $w_{c_{p}}$}

The Hydrometers used to measure specific gravity have graduations of 0.0005 . If we target a working solution (heat transfer fluid) of $40 \%$ Ethylene Glycol in water then, if the measurements are taken at $20^{\circ} \mathrm{C}$, we want a density of $1059.68 \mathrm{~kg} / \mathrm{m}^{3}$ (based on data from ASHRAE Fundamentals 1993, SI version). Hence we need a specific gravity of

$$
\text { S. } .=\frac{1059.68}{998}=1.0618
$$

If we assume that we may only obtain a value to the nearest 0.0005 then $S . G$. may be in the between 1.0615 and 1.0620 which gives a density range of 1059.38 to 1059.87 
$\mathrm{kg} / \mathrm{m}^{3}$. Again, consulting ASHRAE Fundamentals, this leads to a glycol concentration range of 39.79 to $40.14 \%$. More conservatively we may say that the glycol concentration varies by $1 \%$ (i.e. glycol concentration $=40 \% \pm 1 \%$ ).

From the data:

$$
\begin{aligned}
& \text { evaporator outlet temperature }=6.9673^{\circ} \mathrm{C} \\
& \text { evaporator inlet temperature }=12.9993^{\circ} \mathrm{C}
\end{aligned}
$$

The glycol heat capacity will be evaluated at the average of the above temperatures,

$$
\text { Average temperature }=\frac{12.9993+6.9673}{2}=9.9833^{\circ} \mathrm{C}
$$

From ASHRAE Fundamentals, with a temperature of $\approx 10^{\circ} \mathrm{C}$, and a glycol concentration range from $39 \%$ to $41 \%$, the specific heat varies from 3416 to 3453 $\mathrm{J} / \mathrm{kg}{ }^{\circ} \mathrm{C}$. Hence

$$
w_{c_{p}}=\frac{3453-3416}{2}=18.5 \mathrm{~J} / \mathrm{kg}^{\circ} \mathrm{C}
$$

C. Estimate $w_{\Delta T}$

In a separate analysis (not included) a concervative estimate of the uncertainty in the delta $\mathrm{T}$ measurement (via thermopile) is shown to be

$$
w_{\Delta T}=0.04^{\circ} \mathrm{C}
$$

The actual delta $T$, from the data, was 


$$
\Delta T=6.0097^{\circ} \mathrm{C}
$$

Summarizing the data and uncertainties:

\begin{tabular}{|l|l|}
\hline$\dot{Q}_{E}=1880 \mathrm{~W}$ & \\
\hline$\dot{m}=0.0894 \mathrm{~kg} / \mathrm{s}$ & $w_{\dot{m}}=3.58 \times 10^{-4} \mathrm{~kg} / \mathrm{s}$ \\
\hline$c_{p}=3440 \mathrm{~J} / \mathrm{kg}{ }^{\circ} \mathrm{C}$ & $w_{c_{p}}=18.5 \mathrm{~J} / \mathrm{kg}{ }^{\circ} \mathrm{C}$ \\
\hline$\Delta T=6.00{ }^{\circ} \mathrm{C}$ & $w_{\Delta T}=0.0400^{\circ} \mathrm{C}$ \\
\hline
\end{tabular}

Using these numbers in Eqn. 4 yields:

$w_{\dot{Q}_{E}}=\left[\left(3440 \cdot 6.00 \cdot 3.58 \times 10^{-4}\right)^{2}+(0.0894 \cdot 6.00 \cdot 18.5)^{2}+(0.0894 \cdot 3440 \bullet 0.0400)^{2}\right]^{\frac{1}{2}}=17.4 \mathrm{~W}$

Therefore

$$
\begin{gathered}
\dot{Q}_{E}=1880 \pm 20 \mathrm{~W} \\
\text { or } \\
\dot{Q}_{E}=1880 \mathrm{~W} \pm 1 \%
\end{gathered}
$$

\section{COP Uncertainty}

$$
C O P=\frac{\dot{Q}_{E}}{\dot{W}_{\text {comp }}}
$$

where :

$\dot{W}_{\text {comp }}:$ compressor pumping power $(\mathrm{W})$ 
After having performed the appropriate partial derivatives, an uncertainty propagation analysis of Eqn. 5 yields:

$$
w_{C O P}=\left[\left(\frac{w_{\dot{\dot{Q}}_{E}}}{\dot{W}_{\text {comp }}}\right)^{2}+\left(\frac{-\dot{Q}_{E}}{\dot{W}_{\text {comp }}^{2}} w_{\dot{W}_{\text {comp }}}\right)^{2}\right]^{\frac{1}{2}}
$$

Sample Calculation (using data from a heat pump test)

A. Estimate of $w_{\dot{Q}_{E}}$

From the results of section I above:

$$
w_{\dot{Q}_{E}}=17.4 \mathrm{~W}
$$

B. Estimate of $w_{\dot{w}_{\text {comp }}}$

The estimate of the uncertainty in compressor power requires, in and of itself, an uncertainty analysis.

$$
\dot{W}_{c o m p}=\frac{\pi}{30} \tau \bullet r p m
$$

where:

$\tau$ : compressor shaft torque $(\mathrm{N} \cdot \mathrm{m})$ rpm: compressor shaft speed (rev. per minute)

Uncertainty analysis of Eqn. (7) yields:

$$
w_{\dot{w}_{\text {conp }}}=\left[\left(\frac{\pi}{30} \tau w_{r p m}\right)^{2}+\left(\frac{\pi}{30} r p m w_{\tau}\right)^{2}\right]^{\frac{1}{2}}
$$


The manufacturer (Himmelstein) specifications of the torque meter (which also provides rpm data) indicates that the RMS uncertainty on both torque and rpm is $0.15 \%$ of full scale. This gives:

$$
\begin{gathered}
w_{r p m}=22.5 \mathrm{rpm} \\
w_{\tau}=0.0593 \mathrm{~N} \cdot \mathrm{m}
\end{gathered}
$$

Using the same data set as was used in section $\mathrm{I}$, we now have

\begin{tabular}{|l|l|}
\hline$\dot{W}_{c o m p}=389 \mathrm{~W}$ & \\
\hline$r p m=800.0$ & $w_{r p m}=22.5 \mathrm{rpm}$ \\
\hline$\tau=4.64 \mathrm{~N} \cdot \mathrm{m}$ & $w_{\tau}=0.0593 \mathrm{~N} \cdot \mathrm{m}$ \\
\hline
\end{tabular}

Using these numbers in Eqn. 8 gives

$$
w_{\dot{W}_{\text {conp }}}=12.0 \mathrm{~W}
$$

Summarizing the information required for the COP uncertainty calculation:

\begin{tabular}{|c|c|}
\hline$C O P=4.83$ & \\
\hline$\dot{Q}_{E}=1880 \mathrm{~W}$ & $w_{\dot{Q}_{E}}=17.4 \mathrm{~W}$ \\
\hline$\dot{W}_{\text {comp }}=389 \mathrm{~W}$ & $w_{\dot{w}_{\text {comp }}}=12.0 \mathrm{~W}$ \\
\hline
\end{tabular}

Using these numbers in Eqn. 6 gives: 


$$
\begin{gathered}
w_{C O P}=0.156 \\
\text { or } \\
C O P=4.83 \pm 3 \%
\end{gathered}
$$


